\title{
FEMINISMO Y EDUCACIÓN DEMOCRÁTICA
}

Madeleine Arnot*

La historia proporciona pruebas de que dar mayor libertad e igualdad a las mujeres nunca ha puesto en peligro las sociedades democráticas, sino que, por el contrario, las ha fortalecido.

Carlota Bustelo, 1992

Aunque aparentemente tengan muchas cosas en común, el feminismo y la democracia no se han desarrollado a la par. En las economías capitalistas de Europa occidental, sólo en el siglo XIX los ideales de igualdad unieron los movimientos feminista y democrático. En realidad, podemos decir que la igualdad sexual no formaba parte necesaria, ni la forma aún, de la definición de lo que constituye la política democrática. Situando esto en un contexto educativo, no podemos dar por supuesto que todas y cada una de las formas de educación democrática cumplan necesariamente los ideales educativos feministas. Es claro que depende en gran parte de cómo se definan la democracia y la educación democrática.

En consecuencia, son muchas las cuestiones suscitadas por la relación entre feminismo y democracia, sobre todo en el sentido al que se

* Universidad de Cambridge. 
MADELEINE ARNOT

refiere Anne Phillips, una feminista teórica y política, cuando escribe en su libro Engendering Democracy:

En nuestro período, el movimiento contemporáneo de las mujeres ha establecido una conexión particularmente fuerte [entre democracia y feminismo] y, con su resuelta crítica de la jerarquía y su sostenido antiautoritarismo, se ha convertido en un virtual banco de pruebas de los ideales más radicales de la democracia. ${ }^{1}$

En realidad, el éxito de las luchas feministas para elevar la categoría política y económica de las mujeres en las sociedades europeas occidentales es más evidente cuando se utiliza la posición de la mujer como indicador de la medida en que esos países sean democracias "maduras"; en otras palabras, si la retórica democrática coincide con la práctica democrática.

Sin embargo, la tensión entre democracia y feminismo no se expresa con mayor claridad que en las críticas feministas de las estructuras sociales, procesos y actividades de tales sociedades presuntamente democráticas. En el presente estudio, mi objetivo primordial consiste en mostrar cómo los desafíos con respecto a los ideales y la práctica democráticos planteados por las feministas de distintas perspectivas políticas son relevantes para los debates educativos porque afectan a las nociones de la educación democrática.

Para hacer esto, conviene comenzar por una visión general, aunque sea breve, del contexto político de las campañas feministas en la Comunidad Europea. Como veremos, las campañas feministas para mejorar la educación de las mujeres han formado parte de la petición para que las democracias europeas acaben concediendo carta de plena ciudadanía a las mujeres. En parte, estos desafíos (junto con los de los grupos inmigrantes) han recibido la respuesta de la Nueva Derecha,

${ }^{1}$ A. Phillips, Engendering Democracy, 1991, Cambridge, Polity Press, p. 2. 
que ha tenido que redefinir la naturaleza de la ciudadanía y de la política democrática. ${ }^{2}$

A las campañas feministas subyacen determinadas teorías (en especial, la que conocemos como feminismo liberal, vinculada con la teoría democrática liberal). En el segundo apartado de este capítulo, presentaré la política feminista liberal como preludio para introducir las críticas feministas contemporáneas de la democracia liberal. Las críticas como las de las feministas radicales y socialistas y las postmodernistas, más recientes, parten de ciertos supuestos acerca de las relaciones entre los sexos que son relevantes para nuestras discusiones sobre el carácter de la educación democrática. Estas críticas fijan una nueva agenda para la escolarización democrática que tiene especial relieve para la educación política y la preparación ciudadana, y para nuestra forma de entender los derechos de todos los niños a un sistema de educación socialmente justo. ${ }^{3}$

\section{El feminismo y la agenda democrática en Europa}

El número final de Women of Europe, revista publicada por la Comisión de las Comunidades Europeas que trataba de resumir la posición de la mujer en sus estados miembros, presentó algunos aspectos de los efectos de la lucha de la mujer en las últimas décadas. Los países que solemos llamar europeos occidentales han experimentado considerables transformaciones en este siglo, uno de cuyos principales componentes ha sido la lucha de la mujer para asegurar su plena participación en la vida pública. En el informe de cada estado miembro de la comunidad, el período que abarca desde los años sesenta hasta los

${ }^{2}$ M. Arnot, "Feminism, Education and the New Right", en M. Arnot y L. Barton (ed.), Voicing Concerns: sociological perspectives and contemporary education reforms, 1992, Londres, Falmer Press.

${ }^{3}$ Ibidem, y M. Arnot, "Equality and Democracy: a decade of struggle over education", 1991, British Journal of Sociology of Education, 12, 3, p. 447-66. 


\section{MADELEINE ARNOT}

ochenta se caracteriza por las campañas públicas y contundentes a favor del derecho a participar en los procesos democráticos en los niveles internacional, nacional, regional, local y comunitario, y a contribuir plenamente en la esfera económica.

Sin embargo, como sabemos, la lucha de la mujer para que se le ofrezcan y pueda utilizar las oportunidades que supone la plena ciudadanía y para que se la considere en pie de igualdad con los varones no ha carecido de problemas. Como dice Mossuz Lavau, ${ }^{4}$ la historia de Europa está marcada por el progreso y la oposición. Cuando, por ejemplo, se clasifican los estados miembros de la Comunidad Europea según el porcentaje de mujeres presentes en asambleas nacionales y locales, aparecen tres grupos. Incluso en los casos de transformaciones más satisfactorias de las jerarquías políticas de predominio masculino, como Dinamarca, Holanda y Alemania, las mujeres están representadas, como máximo, por sólo un tercio (33\%) de los parlamentarios electos. En España (de la segunda categoría), las mujeres han alcanzado una representación del 14\% mientras que sólo el 10\% de los parlamentarios elegidos en el Reino Unido son mujeres. En algunos casos, las asambleas regionales de estos países (sobre todo en zonas rurales) ofrecen todavía menos oportunidades de participación política formal.

En las tres últimas décadas, se ha utilizado un conjunto de estrategias diferentes dirigidas a mejorar la participación de la mujer en la vida pública en Europa. Hemos observado países que, para garantizar una adecuada representación femenina en la vida política, seleccionan a los parlamentarios electos mediante el sistema de cuotas. Se han empleado normas de igualdad de oportunidades para promover distribuciones más justas por género en la Administración pública y civil, así como legislaciones contra la discriminación, y criterios de financiación dirigida y de financiación igualatoria para mejorar la representación y la participación de las mujeres en otras esferas laborales. ${ }^{5}$ En los paí-

${ }^{4}$ J. Mossuz-Lavau, "European Women in 1992: in transformation", Women of Europe, 70, 1992, p. 12-21.

${ }^{5} \mathrm{M}$. Levy, "France: towards dynamic equilibrium with men", Women of Europe, 70, 1992, p. 43-52. 
ses más progresistas, la provisión estatal de cuidados a los niños pequeños ha ayudado a las mujeres a optar por empleos clave.

Hay una serie de factores que ha influido en la receptividad de distintas naciones europeas ante las demandas de sus respectivos movimientos de mujeres. El crecimiento económico, la reestructuración o la recesión, el desarrollo y la planificación urbanos, las tendencias demográficas y las políticas de inmigración han tenido su repercusión. Sin embargo, un elemento clave para el progreso ha sido el éxito de las campañas de las mujeres para conseguir las mismas o equivalentes carreras educativas que los varones. Las mujeres, como estudiantes, profesoras, madres y políticas, han luchado a favor de los derechos de acceso a las instituciones educativas estatales de masas. En cada nivel, desde la educación infantil hasta la de adultos, las mujeres han defendido el derecho de recibir igual trato (aunque no siempre idéntico) que los varones. Quienes se han comprometido con la justicia social han defendido los derechos de la mujer, no sólo a ser esposas y madres, sino a ser educadas en relación con todas las oportunidades que ofrece la vida pública. Han luchado por sus plenos derechos educativos como ciudadanas de sociedades democráticas.

A algunas mujeres, estas luchas les han supuesto elevados dividendos. Como dice Levy, en el caso de Francia:

Los setenta fueron la década de la eliminación de barreras en los centros universitarios de formación profesional de élite y en los cuerpos públicos; los ochenta han sido la década de los nombramientos para los puestos de mayor prestigio. ${ }^{6}$

$\mathrm{Al}$ afrontar las jerarquías educativas más abiertas, como el acceso a la educación superior, las mujeres quedaron en una posición mucho más fuerte para enfrentarse a las jerarquías políticas en los partidos políticos, en las comisiones gubernamentales y en las estructuras administrativas locales. En algunos casos (como en Francia y España),

${ }^{6}$ M. Levy, op. cit., p. 44. 


\section{MADELEINE ARNOT}

las mujeres han logrado la creación de nuevas organizaciones, ministerios o ambos, con especiales responsabilidades respecto al aumento de la participación económica y política femenina y a la mejora de la vida de la mujer.

En 1993, muchos estados miembros de las Comunidades Europeas presentan porcentajes casi iguales de mujeres estudiantes de educación superior. Como dice Mossuz-Lavau, ${ }^{7}$ este fenómeno es quizá uno de los más significativos de la historia reciente de las mujeres y de las sociedades europeas. En algunos casos, las jóvenes consiguen mejores expedientes académicos que los varones (p. ej.: Francia, Reino Unido); se matriculan en masa en la educación superior, y obtienen un nivel de calificaciones más elevado que nunca. En el Reino Unido, por ejemplo, el número de universitarias es mayor que el de universitarios. En 1984, el 81\% de las estudiantes españolas que realizaron las pruebas de selectividad las superaron, frente al $61 \%$ de los estudiantes varones. Tales éxitos educativos suponen una presión considerable para el acceso a profesiones de élite y modifica la agenda de la reforma en grado importante. Con esos resultados, es difícil hablar de la mujer como "la víctima" del sistema educativo.

92 Al mismo tiempo, las campañas educativas y políticas de las mujeres han puesto de manifiesto la incidencia de las fuerzas del mercado en diversos grupos de mujeres. Si hay un rasgo común que dé unidad a los informes sobre la categoría de la mujer en distintos países, es la creciente conciencia de las desigualdades sociales y económicas significativas entre mujeres. Carlota Bustelo, ${ }^{8}$ por ejemplo, refiriéndose a España, hace hincapié en el impacto de la continuada discriminación patronal contra las mujeres y las dificultades a las que todavía tienen que hacer frente para conseguir empleo, ante las discriminaciones salariales y la degradación de las actividades desarrolladas por mujeres. Distintos grupos de ellas no sólo experimentan de forma diferente la

\footnotetext{
${ }^{7}$ J. Mossuz-Lavau, op. cit.

${ }^{8} \mathrm{C}$. Bustelo, "Spain: changing women, changing society", Women of Europe, 70,1992 , p. 39-42.
} 
dependencia del Estado, sino también el acceso al empleo y las condiciones del mismo -escasez, características, remuneración, ingresos.

La lucha por la igualdad educativa entre los sexos, que constituyó el núcleo del movimiento de la mujer en las últimas décadas ${ }^{9}$ ha dejado, por tanto, una herencia. Como dice un comentarista: "el precio que hay que pagar para que una minoría de mujeres consiga la igualdad con los hombres podría consistir en una mayor desigualdad en el extremo inferior de la escalera". ${ }^{10}$ En efecto, en el contexto inglés, las reformas educativas efectuadas en nombre de la igualdad sexual han estado muy sesgadas a favor de las necesidades de las alumnas académicamente más capaces, de clase media sobre todo, ${ }^{11}$ alterando mucho menos del previsible destino de las chicas de clase trabajadora (dependientes o administrativas de categoría inferior). Ahora bien, dadas las reformas educativas iniciadas por la derecha en el Reino Unido, no cabe duda de que, en vez de reducirse, aumentarán las diferencias entre las carreras educativas de las chicas de clase media y las de clase trabajadora. ${ }^{12}$

Por tanto, la conclusión que puede extraerse de los informes de los estados miembros de la Comunidad Europea es que la democracia misma sigue aún en la agenda de asuntos pendientes. No sólo deben movilizarse todas las mujeres con el fin de que no se malgaste su potencial humano, ${ }^{13}$ sino, como dice Mossuz-Lavau, que el objetivo actual y futuro de los estados miembros de la Comunidad consiste en "convertirse en democracias, en el pleno sentido del término, es decir, regímenes en los que las mujeres tomen parte de la adopción de deci-

${ }^{9}$ M. Arnot, "Equality..., op. cit.

${ }^{10}$ M. Levy, op. cit.

${ }^{11} \mathrm{R}$. Deem, "State policy and ideology in the education of women 19441980", British Journal of Sociology of Education, 2, 2, 1981, p. 131-44 y M. Arnot, "Equality..., op. cit.

${ }^{12} \mathrm{~S}$. Miles y C. Middleton, Girls education in the balance, en M. Flude $y$ M. Hamer (Eds.), The Education Reform Act: its origins and implications, 1988, Londres, Falmer Press.

${ }^{13}$ M. Levy, op. cit. 
siones económicas, políticas y culturales en el mismo plano que los varones." La plena participación democrática y la justicia social son objetivos todavía no alcanzados en estas economías modernas avanzadas.

El problema al que ahora nos enfrentamos consiste en cómo elaborar una nueva agenda política que: a) aborde la resistencia de las divisiones sexuales en la economía y b) otorgue a todas las mujeres plenos derechos como ciudadanas. Una agenda de este tipo para el siglo XXI no puede limitarse a las estrategias contemporáneas a favor de la igualdad política, sino que ha de ocuparse, en un nivel más profundo, de la naturaleza de la democracia.

A la luz de esto, quiero ocuparme de una serie de debates feministas más teóricos que se centran en los conceptos de democracia y de educación democrática. Comenzaré mencionando un debate fundamental de la teoría feminista en el Reino Unido (sobre todo, en países relacionados con las tradiciones filosóficas anglosajonas y anglófonas): la relación entre la teoría feminista y la democracia liberal. Expondré brevemente a continuación los desafíos feministas a la democracia liberal, tanto desde perspectivas estructuralistas como postestructuralistas, señalando cómo han afectado estos debates a la educación. Concluyo con unas indicaciones acerca de dónde se sitúa en la actualidad, a mi modo de ver, el debate sobre la democracia.

\section{Teoría feminista y democracia liberal}

En las sociedades europeas occidentales, el Estado se ha visto obligado a responder a las campañas feministas, cada vez más firmes, organizadas en torno a discursos de ciudadanía y de democracia. ${ }^{14}$ Como señala Heater, en el siglo XX se han intensificado esas luchas, pero nunca quedó claro si la oposición a conceder ciudadanía plena a la mujer se derivaba de "la apatía o de la consideración de su utilidad."

${ }^{14}$ D. Heater, Citizenship: the civic ideal in world history, politics and evaluation, 1990, Londres, Longman. 
No obstante, de estas luchas hemos aprendido cómo las políticas y discursos educativos oficiales "construían" la imagen de la mujer. Las historiadoras feministas han señalado el impacto de los discursos sobre la eugenesia, el patriotismo, el racionalismo económico y, más tarde, las ideas del bienestar que restringieron y circunscribieron la educación femenina a determinadas tradiciones curriculares. Estas tradiciones que regulaban la educación de la mujer definían su papel privilegiando los aspectos domésticos y de crianza, y poniendo énfasis en una educación profesional centrada en las personas más que en un campo concreto. Se educaba a las mujeres como hijas de la nación, infundiéndoles un sentido del deber y de servicio a la sociedad y a sus hombres. ${ }^{15}$

Todos esos discursos tenían en común la construcción de una categoría de "mujer". En los discursos educativos de los siglos XIX y XX se incluyen los conceptos de categoría y destino sociales femeninos; personalidades femeninas; capacidades, necesidades e intereses de la mujer. Mientras los varones se distinguían según los patrones de las desigualdades sociales, las mujeres se describían mediante características esenciales biológicas, psicológicas o ambas. Las mujeres (a pesar de sus diferencias con respecto a la categoría social y experiencias vitales) en estos discursos educativos quedaban categorizadas en un plano más homogéneo que heterogéneo.

En Inglaterra, la solución consistió en establecer para las mujeres un sistema casi paralelo al organizado para los jóvenes y su futuro profesional claramente diferenciado. ${ }^{16}$ En realidad, podría demostrarse el mito de la independencia de clase de la mujer mediante esta legitimación de la educación femenina más o menos homogénea, al tiempo que

${ }^{15} \mathrm{C}$. Dyehouse, "Social Darwinistic ideas and the development of women's education in England 1880-1920", History of Education, 5, 1, 1976, p. 4158 y A. Davin, "Imperialism and motherhood", History Workshop Journal, 5, primavera, 1978, p. 9-65.

${ }^{16} \mathrm{M}$. Arnot, "A crisis in patriarchy? British feminist educational politics and state regulation of gender", en M. Arnot y K. Weiler (ed.), Feminism and Social Justice in Education, 1993, Londres, Falmer Press. 


\section{MADELEINE ARNOT}

se negaban a la mujer los privilegios educativos y sociales que algunos varones adquirían por medio de la escolarización. ${ }^{17}$ En los años cuarenta, estas pautas educativas, diferentes según el género, se convirtieron en un aspecto indiscutido de la sociedad de la posguerra, preocupada por el desarrollo de un Estado democrático liberal.

El desafío a esta universalización de los requisitos educativos de la mujer y de las pautas de diferenciación según el género relacionadas con ellos se desarrolló al crecer el movimiento de la mujer que, a mi modo de ver, tomó dos direcciones distintas: el feminismo democrático liberal y el igualitarismo radical. En los dos apartados siguientes, expondré la relación entre estas dos tradiciones.

\section{El feminismo democrático liberal y la reforma educativa}

A la mayoría de la gente le resulta familiar el carácter del feminismo liberal en la educación. Las críticas iniciales a sus limitaciones, de las que me he ocupado en otros lugares, ${ }^{18}$ han dado paso ahora a una mayor comprensión de la significación e impacto políticos de esta tra-

96 dición. Hay que señalar que el trabajo de las feministas liberales en su lucha a favor de la mujer para tener acceso a las formas masculinas de educación de categoría superior tuvo éxito al desafiar a algunas de las instituciones más elitistas y jerárquicas de nuestra sociedad. Como dice Connell, ${ }^{19}$ llevaron a cabo un ataque "formidable y sostenido" contra

${ }^{17}$ Ibidem.

${ }^{18}$ M. Arnot, "La coeducación y la lucha por una educación antisexista en el Reino Unido", Mujer y educación. El sexismo en la enseñanza, 1989, Instituto de Ciencias de la Educación de la Universidad Autónoma de Barcelona y "La época del igualitarismo. La política y la práctica feministas contemporáneas en educación en el Reino Unido", en P. Ballarin Domingo (ed.), Desde las mujeres: modelos educativos: coeducar/segregar, 1992, Univ. de Granada.

${ }^{19}$ R. W. Connell, "The State, Gender and Sexual Politics", Theory and Society, 19, 1990, p. 507-44. 
una de las instituciones clave de las sociedades democráticas, utilizando la retórica propia de la misma democracia.

Las feministas liberales rechazaron lo que consideraban una educación de segunda clase que se daba a las jóvenes. Se opusieron a la categoría subordinada de la mujer en la esfera pública -más notable en los campos políticos y económicos- defendiendo los derechos de las mujeres como individuos a desarrollar su máximo potencial en esas sociedades. En cuanto individuos, las mujeres no sólo tenían derecho a ser educadas para ser esposas y hermanas, sino a recibir una educación que les llevara a ocupar su lugar en el ámbito público.

Las feministas liberales tomaron como punto de partida la demostración de las desigualdades sexuales en el sistema educativo. Las estadísticas de la educación que elaboraron pusieron en evidencia las grietas de las sociedades democráticas. Es más, al producir datos estadísticos, revelaron de qué forma los hombres habían hecho suyo el Estado, el cual, según el liberalismo, debería haber sido un árbitro neutral. Demostraron hasta qué punto el Estado era, en realidad, una fraternidad, en la que los varones dominaban las maquinarias mediante las que se definía la justicia social.

Al mismo tiempo, pusieron de manifiesto la medida de la segregación laboral según el sexo. La evidencia estadística mostraba las incompatibilidades entre la democracia y el capitalismo. Con intención o sin ella, las campañas feministas liberales desenmascararon el fracaso y los límites de las sociedades democráticas liberales a la hora de dar a la mujer algo más que una categoría secundaria y marginal.

No obstante, las campañas educativas feministas liberales se llevaron a cabo con las "libertades" y "espacios" que proporcionaba la democracia liberal. El objetivo consistía en eliminar los obstáculos que se oponían a las auténticas libertades de elección, movimiento, maniobra y acción en el sistema educativo. Sin embargo, el efecto de las iniciativas educativas desarrolladas en nombre de la igualdad de oportunidades para ambos sexos fue contraproducente. En vez de poner de manifiesto los niveles posibles de libertad en las sociedades capitalistas, esas reformas demostraron la necesidad de políticas centralizadas 


\section{MADELEINE ARNOT}

impuestas en nombre de la igualdad de sexos. Donde se promovía la libertad de elección curricular, la diferenciación por género configuraba la pauta de tal elección. Donde se permitía la libertad de juego, se daba paso al acoso sexual y al abuso verbal. Donde se promovía la libertad de expresión, se manifestaba un lenguaje sexista. Donde se valoraba la autonomía del maestro y de la escuela, se descubría la discriminación sexual contra las maestras y quedaban marginadas las cuestiones de género. ${ }^{20}$

Paradójicamente, en el Reino Unido, el éxito y la significación de estas campañas se cifraron en la especial relación entre el feminismo liberal y el Estado democrático liberal de posguerra. E1 feminismo democrático liberal había explotado la versión de la ciudadanía propuesta al finalizar la Segunda Guerra Mundial. En este período, era clave la idea de la regeneración social, haciendo hincapié en una sociedad más justa, abierta y moderna. T. H. Marshall, influyente comentarista social que escribía en los años cincuenta, resaltaba la significación de lo que definía como nuevo concepto de ciudadanía: el de ciudadanía social, que completaba y ampliaba definiciones anteriores. Marshall (1950) decía que los nuevos valores de la ciudadanía social completaban, por una parte, el elemento civil y, por otra, el político del concepto de ciudadanía elaborado durante el siglo anterior. Mientras que el elemento civil se refiere a la libertad de la persona-libertad de expresión, pensamiento y creencia, derecho a la propiedad, a celebrar contratos válidos y a la justicia-el elemento político se refiere al derecho a participar en el ejercicio del poder político por medio de los representantes políticos o como elector. Marshall llama elemento social a:

todo lo que abarca desde el derecho a un mínimo de bienestar $\mathrm{y}$ de seguridad económicos hasta el derecho a participar al máximo de la herencia social y a vivir una vida civilizada, de acuerdo con el nivel prevaleciente en la sociedad. ${ }^{21}$

${ }^{20}$ Cfr. M. Arnot, "Equality..., op. cit. y "A crisis..., op. cit.

${ }^{21}$ T. H. Marshall, 1950, p. 10; cit. en House of Commons, 1990, p. 5. 
En los años sesenta, se insistía en un "mínimo de derechos": los de todos los individuos a que el Estado satisfaciera sus necesidades básicas (p. ej., vivienda, alimentación y educación). El feminismo, como uno de los movimientos sociales de ese período, se ocupó de esta renovación y del desarrollo del concepto de ciudadanía social, aunque, como dice Yeatman, ${ }^{22}$ refiriéndose a una evolución parecida en Australia, el nuevo modelo de Estado, con su compromiso con la beneficencia, "no emitió ningún mensaje igualitario".

Es significativo que las feministas democráticas liberales volvieron el concepto de derechos "contra el modelo patriarcal de ciudadanía". 23 Llevaron a cabo un análisis "potente y agudo" de la dominancia masculina en la mayoría de las instituciones gubernativas (una de las cuales era la educación).

Por tanto, el impacto de las campañas feministas democráticas liberales tuvo mayores consecuencias que las meras tentativas de mejorar las experiencias de las alumnas y profesoras de escuelas, centros superiores y universidades, y que la modificación de las actitudes con respecto al papel de los sexos. Aunque se incluyan en los discursos democráticos liberales, paradójicamente, la obra feminista liberal respalda, en vez de rechazarlas, las conclusiones de las teóricas políticas feministas, que parten de la elaboración de una crítica profunda de la teoría democrática liberal.

\section{La democracia liberal bajo el ataque feminista}

Para dar una idea del tenor de este debate, remitámonos a la obra de Carol Pateman, una pensadora líder y muy influyente en este campo, que pone de manifiesto cómo los teóricos políticos clásicos construyeron los conceptos del contrato social, la idea de consentimiento y el

${ }^{22}$ A. Yeatman, Bureaucrats, Technocrats and Democrats, 1990, Sydney, Allen and Unwin.

${ }^{23}$ R. W. Connell, op. cit. 


\section{MADELEINE ARNOT}

mismo carácter de la democracia en relación con los hombres. Pateman sostiene que el concepto de ciudadanía elaborado por los teóricos ingleses era lo que Marx llamaba "piel política dé león", que las mujeres sólo se ponen a veces y con reticencias. En Disorder of Women, dice que esta piel política de león

...tiene una gran melena y pertenecía a un león, es una vestimenta masculina. Cuando, por fin, las mujeres conquistan el derecho a vestir la piel de león, les queda muy mal y, por tanto, resulta indecorosa.

Análisis como los de Pateman, Yeatman ${ }^{25}$ y Lloyd $^{26}$ demuestran que los conceptos de "político", "sociedad civil" e incluso "democracia" definidos por Rousseau, Kant y Hegel (filósofos europeos por excelencia) están sesgados, en el nivel de definición, con respecto al género. En estos escritos comienzan a salir a la superficie, por ejemplo, las conexiones entre las formas de definir la idea de orden social en relación con el desorden, por una parte, y las formas de definir lo masculino y lo femenino, por otra.

100 Pateman sostiene que la filosofía política predominante ha utilizado el concepto de orden para referirse a la idea de una individualidad racional y autónoma, según la cual los individuos actúan de acuerdo con principios morales universales y objetivos, trascendiendo los intereses privados. Sin embargo, el origen de tales ideas de individuo y de los principios de la acción es una versión europea occidental de la masculinidad. Para los filósofos políticos europeos, varones en su mayoría, los hombres ejemplifican el potencial de los humanos para crear un orden social basado en la racionalidad y en la verdad.

${ }^{24}$ C. Pateman, The Disorder of Women, 1989, Cambridge, Polity Press, p. 6.

${ }^{25}$ A. Yeatman, op. cit.

${ }^{26}$ G. Lloyd, "Selfhood, war and masculinity", en C. Pateman y E. Gross (ed.), Feminist challenges: Social and Political Theory, 1986, Sidney, Allen and Unwin. 
En el otro lado de la ecuación, el del desorden, encontramos a las mujeres, representadas por sus "intereses individuales degradantes" (Kant) y la imposibilidad de que produzcan una conciencia ética (Hegel). ${ }^{27}$ El desorden político de las mujeres significa que deben quedar excluidas del contrato social original $o$, en realidad, del pacto fraternal que es la base de la sociedad. ${ }^{28}$

Desde esta perspectiva, la teoría democrática liberal no sólo ha construido un conjunto de categorías universalizadoras antagonistas de masculino y femenino, sino que les ha atribuido determinadas características que afectan a la categoría social de hombres y mujeres como ciudadanos. La filosofia democrática liberal estructura el carácter propio de la mujer como algo que "ha de trascenderse para constituirse en ciudadano". ${ }^{29}$ Las mujeres son símbolos de la emoción, del sentimiento natural, del cuidado hacia quienes están relacionados con ellas. Da la sensación de que no son capaces de la objetividad ni de la conducta fundada en principios, que caracterizan precisamente al soldado y al ciudadano.

Si las teóricas políticas feministas tienen razón, en el núcleo más profundo de nuestra visión de la sociedad y de la ciudadanía democrática se presumen diferencias entre hombres y mujeres, así como una estructuración del mundo según el género que respalda tales divisiones. Por tanto, la separación de las esferas pública y privada sería representativa de la distinción entre lo masculino y lo femenino. En la esfera pública, los varones son dueños de sí mismos; en la esfera privada, las mujeres son dominadas por los hombres. Éstos, al trascender el dominio privado, se convierten en sociales, mientras que el discurso democrático liberal sitúa a las mujeres como parte y símbolo del terreno privado, excluyéndolas, por definición, del orden social (civilizado).

Desde esta perspectiva, es evidente que las mujeres no pueden introducirse en el campo (o campo de batalla) público sin provocar

\footnotetext{
${ }^{27}$ G. Lloyd, op. cit.

${ }^{28}$ Cfr. C. Pateman, op. cit.

${ }^{29} \mathrm{G}$. Lloyd, op. cit.
} 


\section{MADELEINE ARNOT}

importantes trastornos. ${ }^{30}$ Las campañas feministas para romper las delimitaciones según el género de las esferas pública y privada o, incluso, la mera consecución de la igualdad de la mujer en la esfera pública ataca el núcleo del discurso de la democracia marcado por el género.

Volviendo sobre la significación de las campañas feministas liberales en la educación, vemos con mucha mayor claridad la posición que adopta ese discurso, no sólo en el contexto histórico inmediato de la beneficencia y de la ciudadanía social de posguerra, sino, en un nivel más profundo, en los principios masculinizados de lo que constituye la democracia. Las feministas democráticas liberales parten de la base indiscutida de este discurso marcado por el género, concentrando todos sus esfuerzos en la campaña activa a favor de una mayor participación de la mujer en la esfera pública. En este contexto, la democratización de la educación significaba urgir a las mujeres a que participaran más plenamente en la esfera pública, reclamando materias no tradicionales y cursos de orientación profesional y cambiando sus actitudes con respecto al papel de la mujer en la sociedad. La educación democrática significaría poner el potencial intelectual de las mujeres en la economía. La educación democrática significa, pues, educación no marcada por el género, en la que éste no supondría ya una restricción para las mujeres en cuanto a su aprovechamiento individual. ${ }^{31}$

Paradójicamente, en el feminismo democrático liberal, el Estado tendría que desempeñar el papel de promotor de la reforma progresiva y ocuparse de las mujeres y de sus intereses. Las pruebas indicadas al principio de este capítulo muestran que, en algunos países europeos, las condiciones económicas eran tales que este tipo de compromiso político para eliminar los sesgos por género de la vida pública lo hacía posible (aunque es probable que no sin ciertas luchas y oposición). Pero, como también revelan los informes de las Comunidades Europeas, las mujeres todavía no han logrado una participación equiparable a la de los varones en los procesos de decisión; incluso y de mayor signifi-

${ }^{30}$ C. Pateman, op. cit.
${ }^{31}$ M. Arnot, "A crisis..., op. cit. 
FEMINISMO Y EDUCACIÓN

cación aún, las pautas económicas y sociales de desigualdad sexual permanecen sin cambios.

Dado este enfoque, no puede sorprender a nadie que la posición de la mujer en la familia sea aún profundamente problemática. El sufragio, la educación obligatoria de masas, incluso los efectos de las dos guerras mundiales no han liberado a la mujer de su destino doméstico. La expansión de la educación secundaria y superior tras la Segunda Guerra Mundial, si acaso, puso de manifiesto el control masculino del ámbito político. Y no parece que exista gran fundamento para justificar ese dominio. ${ }^{32}$

La estrategia de las feministas liberales para eliminar las diferencias según el género no ha conseguido cuestionar la estructuración más fundamental del discurso democrático. Con su compromiso a favor del aprovechamiento educativo de las jóvenes y la política de derechos, el feminismo liberal ha abstraído a la mujer de su historia y situación sociales. En este discurso, la mujer seguía siendo una categoría unitaria. Aparte de los compromisos domésticos y, quizá, del deseo de papeles sociales dobles, en el trabajo y en la familia, no es fácil distinguir las necesidades, derechos o deberes masculinos y femeninos. Las feministas liberales se han centrado en las contradicciones más patentes de la democracia capitalista, pero no han conseguido descubrir obstáculos mucho más profundos para la igualdad sexual.

\section{Mujer, maternalismo y educación democrática}

Vayamos ahora al segundo conjunto de respuestas, a la estructuración histórica de la educación femenina y a la categorización de las mujeres. Gran parte de la teoría política feminista, más que la teoría educativa feminista, está marcada por la idea de diferencia. Las mujeres -dicen algunos- por el carácter de su posición en las esferas pública y privada y su papel como madres y profesionales, son únicas y claramente dis-

\section{${ }^{32}$ Ibidem.}




\section{MADELEINE ARNOT}

tintas de los hombres. Las diferencias de género hacen significativo el hecho de que los varones dominen la maquinaria del gobierno, que las formas de autoridad se asocien con determinadas versiones europeas del poder sexual masculino ${ }^{33}$ y que los discursos políticos privilegien la experiencia masculina. Después de todo, si hombres y mujeres son iguales ¿importa acaso ese dominio de un sexo?

El desarrollo de versiones igualitarias más radicales del feminismo a finales de los años sesenta puso de manifiesto los límites de un concepto de derecho democrático referido sólo a la esfera pública $(\mathrm{y}$, por implicación, los del concepto de ciudadanía social y del de democracia participativa, desarrollados después de la guerra). Visto en retrospectiva, la clave de la postura feminista radical era la relación entre la familia y la democracia y no sólo entre la familia y el capitalismo. Como dice Anne Phillips:

Para las feministas, el fracaso de la exploración del carácter de la mayor parte de la esfera privada es un fracaso en el debate democrático. $^{34}$

104 Por una parte, Phillips dice que las desigualdades en el matrimonio y en el hogar dejan sin sentido la igualdad de derechos políticos. Por otra, ¿es posible que el "individuo" descrito por la teoría democrática liberal, abstraido de las relaciones familiares, sea incluso una mujer? Como individuos, ¿las mujeres eran tan autónomas y libres? ¿Podría reconocer la democracia liberal que la mujer, en virtud de su subordinación, tiene mucha menos libertad que el hombre?

En la familia, la categoría política de la mujer se define mediante el contrato matrimonial, el cual, a diferencia del contrato basado en principios mercantiles, no supone el consentimiento. Aquí, la mujer carece de derechos que la protejan de la violencia física y mental de sus maridos. Aquí, la libertad individual se sustituye por la dependencia

\footnotetext{
${ }^{33}$ R.W. Connell, op. cit.

${ }^{34}$ A. Phillips, op. cit., p. 30.
} 
económica; la categoría de las mujeres como individuos es incierta y ambigua. En la familia, parece que las mujeres se definen menos por la teoría liberal que por los discursos patriarcales que resaltan las restricciones y no la libertad; no la igualdad de valor, sino la subordinación. ${ }^{35}$ Podríamos decir que la teoría liberal presume que los varones son los dueños de las mujeres en el hogar. ¿Qué importa aquí la democracia?

Desde una perspectiva feminista radical, la condición de la liberación de la mujer no se basa en los conceptos de igualdad e igualdad de derechos, ni siquiera en las libertades democráticas de los discursos democráticos liberales. Da la sensación de que, cada vez más, las feministas saben que, aunque la igualdad de derechos sea el requisito mínimo para impedir la descalificación de la mujer, no garantiza su liberación. $^{36}$

Rowbothan, ${ }^{37}$ en su análisis retrospectivo del movimiento de la mujer en el Reino Unido, reflexiona sobre el impacto de las campañas feministas sobre la democracia. Lo que deseábamos en los años setenta-dice--era, en realidad, la "ampliación" de la definición de democracia, para referirla cada vez más a la esfera privada. La desigualdad doméstica, la identidad, el control sobre la sexualidad se incluían en la nueva democratización de las relaciones humanas. Había que introducir la vida cotidiana en las dimensiones ensanchadas de la democracia. Las nuevas estrategias feministas radicales se centraban menos en las estructuras objetivas de la sociedad y más en las subjetividades (utilizando menos el Estado y más los tratamientos terapéuticos y psicoanalíticos). Las fantasías y deseos individuales crearon un nuevo "terreno" para la democracia y, en potencia, un nuevo centro de atención para quienes se preocupaban de democratizar la educación. Cada vez más,

${ }^{35}$ A. Phillips, op. cit.

${ }^{36} \mathrm{M}$. Thornton, "Sex equality is not enough for feminism", en C. Pateman y E. Gross (ed.), Feminist Challenges: social and political theory, 1986, Sydney, Allen and Unwin.

${ }^{37}$ S. Rowbothan, "Feminism and democracy", en D. Held y C. Pollitt (ed.), New Forms and Democracy, 1986, OU/Sage. 


\section{MADELEINE ARNOT}

la orientación y la educación social se utilizarían para transformar las relaciones personales y no sólo las relaciones escolares estructuradas según el género.

Sin embargo, estas nuevas estrategias democratizadoras sólo conseguirían la liberación de la mujer si se encontraba un conjunto de valores diferente del de los discursos políticos masculinos. En este sentido, tuvieron una significación creciente los escritos de filósofas y psicólogas feministas (en especial norteamericanas como Carol Gilligan y Madeleine Grumet), que señalaron valores morales alternativos y formas de pensar de las mujeres jóvenes que contrastaban con los de los varones. A través de estas investigaciones, las chicas y las mujeres parecían tener diferentes conjuntos de criterios y prácticas éticos, distintas concepciones de la justicia social. Esos valores, fuesen el resultado de su diferencia psicológica o de sus experiencias marcadas por el género desde la infancia, parecían reflejar formas distintas de conocer y evaluar el mundo. Si así fuera, existía la posibilidad de construir un marco político alternativo al de la democracia liberal.

Para las feministas que apoyaban las ideas de la diferencia entre masculino y femenino, la estrategia educativa consistiría en "revaluar"

106 lo femenino, privilegiar las ideas femeninas de humanidad. Desde esta perspectiva, las escuelas tendrían que reemplazar los valores más violentos, competitivos y militaristas de las sociedades democráticas liberales, resaltando los valores y la ética femeninos. La escolarización tendría que ocuparse de la educación de los niños en los valores de una sociedad acogedora, cariñosa y pacífica. El curriculum subrayaría la importancia de la subjetividad, la imaginación, la estética y la emoción, la comunicación y la colaboración o la empatía, en vez de los estilos de debate conflictivos y combativos.

La clave de esta nueva forma de orden social no sería la "hermandad del hombre", sino las relaciones entre madre e hijo en la familia. ${ }^{38}$ Las feministas profamilia defienden el carácter fundamental de las relacio-

${ }^{38}$ M. G. Dietz, "Citizenship with a feminist face: the problem with maternal thinking", Political Theory, 1985, febrero, p. 31. 
nes maternales para la reestructuración de la conciencia política y el establecimiento de un marco de referencia que Elshtain ${ }^{39}$ llama "feminismo social".

Las consecuencias de tal argumento para la democratización de la educación son muy amplias. Una universidad basada en este orden femenino, por ejemplo, transformaría sus modos de enseñanza, aprendizaje y evaluación de manera que la cooperación, colaboración y apoyo mutuo serían aspectos fundamentales del aprendizaje. Belenky y otras, ${ }^{40}$ en un influyente texto titulado Women's Ways of Knowing, resaltan lo que ellas llaman formas de aprendizaje de la mujer con respecto al mundo y a las consecuencias para la estructuración del saber educativo. Las mujeres, dicen, mantienen una relación diferente con el saber, que privilegia los valores humanísticos y la conexión entre las esferas de la actividad y el conocimiento. Desaparecería la especialización y fragmentación del conocimiento que caracteriza a la educación actual. En cambio, siguiendo a Paulo Freire, ${ }^{41}$ que afirmaba que el conocimiento se adquiriría en un círculo de aprendices, la enseñanza sería dialógica, los estudiantes se formarían mejor, las mujeres aportarían sus propias versiones de la verdad. ${ }^{42}$ Otras $^{43}$ hacen hincapié en las formas de autoridad maternal que las mujeres, en cuanto educadoras, pueden aportar a los ambientes de aprendizaje, y en las formas de lucha de ellas contra las estructuras paternales.

${ }^{39}$ J. B. Elstain, Public Man, Private Women, 1981, Princeton University Press.

${ }^{40}$ M. F. Belenky, B. M. Clinchy, N. R. Goldberger y J. M. Tarule, Women's Ways of Knowing, 1969, Nueva York, Basic Books.

${ }^{41}$ P. Freire, Pedagogy of the Oppressed, 1970, Nueva York, Herder and Herder. (Trad. cast.: Pedagogía del oprimido, 1992, Madrid, Siglo XXI, 12a. ed.)

${ }^{42}$ Cfr. Maher, 1985.

${ }^{43}$ Cfr. M. Culley y C. Portuges (ed.), Gendered Subjects: the dynamics of feminist teaching, 1985, RKP. 


\section{MADELEINE ARNOT}

Las cuestiones suscitadas por el feminismo social resultan, en efecto, provocadoras para el pensamiento y recuerdan, de muchas formas, debates anteriores sobre la pedagogía crítica y la conciencia crítica. Los estilos de aprendizaje que suponen tales estrategias implican, de nuevo, un proceso de desestructuración y reconstrucción del lenguaje, los conceptos y las teorías. Los maestros, utilizando distintas estrategias de "personalización", estimularían a los alumnos a reflexionar sobre sus propias vidas y la construcción de sus identidades (mediante historias de vida, autobiografias, diarios, etc.).

En esta versión de lo que podríamos llamar "práctica democrática radical", es clave la importancia de capacitar a la mujer para controlar su propia vida y participar en decisiones que afectan a ésta. Este proceso no es individual, sino colectivo, resaltando y utilizando las experiencias comunes como medio para impulsar la liberación. La oposición y la participación políticas se hacen posibles mediante la proclamación de la subjetividad femenina y el estímulo para que las mujeres construyan sus propias narraciones.

Sin duda, es discutible si estas pedagogías feministas, brevemente descritas aquí, son viables en un sistema educativo de masas. En rea-

108 lidad, podrían desarrollarse en el sector informal, sobre todo en la educación de adultos y en los cursos de acceso. Podemos decir que la falta de representación femenina en las instituciones educativas controladas por los varones hace casi imposible instrumentar estas perspectivas feministas, pero hemos de reconocer también la interconexión del conocimiento escolar con las estructuras económicas y la incompatibilidad de esas formas de enseñanza y aprendizaje con los sectores industriales más tradicionales y la demanda de una mano de obra fragmentada, con diferente preparación y organizada de forma jerárquica.

Sólo en circunstancias excepcionales, los responsables de la política educativa han reconocido la significación de los argumentos feministas a favor de las políticas de igualdad de oportunidades, y comenzado a hacerse cargo de las diferencias entre las culturas masculina y femenina (p. ej.: Elgovist y Saltzman, exponen cómo, en Suecia, los reformadores de la educación han tenido que aceptar y trabajar con las 
FEMINISMO Y EDUCACIÓN

diferencias entre las "vías rectas" y las "sendas tortuosas" masculinas y femeninas). ${ }^{44}$

\section{El reconocimiento de la diferencia}

La democratización de la educación podría haber sido un asunto relativamente sencillo si sólo consistiera en incluir la cultura de la mujer y los valores del mundo privado en nuestra comprensión de lo que constituye la democracia. Sin embargo, como sabemos, el concepto de cultura femenina es problemático, dado que implica argumentos esencialistas biológicos o culturales y universaliza la influencia del maternalismo de manera inaceptable. Mientras que el feminismo democrático liberal concebía la categoría de la mujer como individuo, el feminismo radical parece construir un sujeto nuevo: "la mujer como madre".

Hemos aprendido que hay que incluir el ámbito privado en las definiciones de democracia y de educación democrática para que la mujer se convierta en ciudadana con participación plena. Pero todavía quedan cuestiones sin responder acerca de cómo puede el feminismo configurar una versión nueva de la democracia y de la educación democrática.

Otras teóricas políticas muestran una historia más compleja en la que sólo puede hablarse de las mujeres y de la educación femenina en términos de las diferencias entre mujeres (y no sólo de sus diferencias con respecto a los hombres). Por ejemplo, la conciencia creciente de la medida de las desigualdades sociales entre las mujeres niega la simplicidad de tales argumentos. El feminismo socialista ha demostrado, si acaso, diferencias significativas en las relaciones de las mujeres de clase trabajadora y de las de clase media con las economías capitalistas. Asimismo, han puesto de manifiesto el poder que las últimas ejercen

${ }^{44}$ Elgovist-Saltzman, "Straight Roads and Winding Tracks: Swedish educational policy from a gender equality perspective", Gender and Education, 4, 1-2, 1992, p. 41-56. 
sobre las primeras. Sin embargo, las teorías de la democracia liberal, las teorias socialistas (sobre todo las de la educación y de la reproducción social) no sólo han tendido a reforzar la distinción entre las esferas pública y privada, sino que han fracasado a la hora de definir lo que significa la participación democrática en el hogar. Como indica Jagger, ${ }^{45}$ las feministas socialistas sólo ofrecen una respuesta confusa a la cuestión de la democracia en el hogar. La lógica de su postura supone que, si el control democrático de la economía es esencial, también será esencial tener un control democrático sobre la reproducción biológica. En este contexto, las feministas socialistas defienden el derecho de la mujer sobre su propio cuerpo, pero también, de forma un tanto contradictoria, la necesidad del control de la comunidad sobre la reproducción biológica, en nombre del bien común. Si éste hubiera de ser el objetivo, ¿en qué consistiría la enseñanza de la educación sexual?, ¿en la coerción pública del derecho individual de la mujer a tener hijos?

En general, la perspectiva socialista sobre la educación para la democracia no se ha ocupado de estos espinosos problemas. La imagen de una educación democrática radical solía llevar consigo la celebración de la conciencia radical a través de una pedagogía curricular y

110 crítica alternativa. El origen de esa radicalización estaba, por regla general, en las formas de conocimiento y en los valores culturales de las clases trabajadoras industriales masculinas. Esas estrategias radicales se detenían antes de cuestionar el predominio masculino en la esfera privada. Era difícil que el predominio de la cultura burguesa masculina señalada por teóricos franceses como Bourdieu y Passeron, ${ }^{46}$ fuera reemplazada por una cultura feminizada, como tampoco los "maestros críticos" cuestionarían necesariamente las formas de autoridad masculina que respaldaban aquella cultura. En realidad, a la luz de

${ }^{45}$ A. M. Jagger, Feminist Politics and Human Nature, 1983, Rowman and A. Held, Harvester.

${ }^{46}$ P. Bourdieu y C. Passeron, Reproduction in Education, Society and Culture, 1977, Sage. (Trad. cast.. La reproducción. Elementos para una teoría del sistema de enseñanza, 1977, Barcelona, Laia.) 
la versión de la democracia participativa desarrollada por Left, parece difícil que se cuestionen las formas de subjetividad y las relaciones personales que apoyan la marginalidad de la mujer.

Puede decirse que las feministas socialistas tampoco consiguieron elaborar un concepto liberador de la educación democrática. Jagger dice que se centró la atención de manera demasiado estricta en las relaciones adultas entre hombre y mujer, otorgando muy poca importancia a los derechos de los niños. Al tratar el tema de la igualdad, se ha pasado por alto la cuestión del derecho de los niños a participar en las decisiones que les afectan. En efecto, es rara la iniciativa basada en la escuela que incluya a los niños en todas las etapas de la elaboración de normas igualitarias. En la mayoría de los casos, es la maestra feminista radicalizada quien actúa como agente de cambio, en nombre de la igualdad sexual.

No obstante, las feministas socialistas examinaban cualquier análisis que partiera del supuesto de la categoría unitaria de "mujer". Sus análisis, con las críticas feministas negras con ellos relacionadas, demostraron las relaciones de explotación y opresión que existían entre mujeres. Cada vez más, los estudiosos universitarios fueron cayendo en la cuenta de la necesidad de describir distintas formas de feminidad, discursos que reflejan diferentes posturas de mujeres y estructuras diferentes en las que se encuadran las diversas clases de mujeres. A principios de los años ochenta, la diferencia de género estaba claramente sobre el tapete.

\section{Las perspectivas educativas feministas y la época moderna y postmoderna}

Poco antes de abrirse el debate entre los feminismos liberal, radical y socialista, comenzaron a considerarse esas perspectivas como respuestas históricas concretas a la democracia liberal, presionando a favor del cambio, aunque sea muy significativo el hecho de que se definieran de acuerdo con los supuestos del mismo discurso democrático liberal. 


\section{MADELEINE ARNOT}

El centro de atención y la configuración de las perspectivas feministas sobre la educación empezaron a considerarse como discursos históricos específicos fundados en lo que Middleton ${ }^{47}$ llama "narraciones principales" de la era moderna, y configurados por éstas.

Esas teorías estructurales construyeron una versión del orden social que establecía esencialmente explicaciones causales. Las carreras educativas de las mujeres eran el resultado, por ejemplo, de pautas de socialización marcadas por el género, la explotación capitalista o la opresión de las mujeres ejercida por los hombres. En los casos del feminismo liberal o del radical, las experiencias de las mujeres se universalizaron. En el caso del feminismo socialista, se redujeron a la determinación de clase.

Parece que tales explicaciones guardan poca relación con la complejidad de las identidades, experiencias, culturas y posiciones sociales de las mujeres. Las feministas postestructurales y postmodernas, como Walkerdine, ${ }^{48}$ defienden la necesidad de reconocer las distintas formas de representar a las mujeres en los diversos discursos. En su análisis, las maestras y las alumnas aparecen representadas mediante los distintos discursos de la sexualidad, el género, las ideologías progresistas cen-

112 tradas en el niño, etc. Con frecuencia, esos discursos son incompatibles y contradictorios. Del mismo modo, Lather ${ }^{49}$ defiende la importancia del reconocimiento de diferentes estructuras narrativas que otorgan significado a las experiencias y acciones de las mujeres y las niñas. Desde esta perspectiva, la categoría de "mujer" aparece como equivalente a una forma literaria: la "mujer" existe como tema de un discurso.

No obstante, estas perspectivas, de las que no podemos ocuparnos con profundidad aquí, no sólo cuestionan las explicaciones de las experiencias educativas de las niñas que ofrecen las pedagogas feminis-

${ }^{47} \mathrm{~S}$. Middleton, "A post modern pedagogy for the sociology of women's education", en M. Arnot y K. Weiler (Eds.), Feminism and Social Justice in Education, 1993, Londres, Falmer Press.

${ }^{48}$ V. Walkerdine, School Girl Fictions, 1990, Londres, Verso.

${ }^{49}$ P. Lather, Getting Smart, 1991, Nueva York, Routledge. 
tas, sino también las formas de representar y llevar a cabo la lucha democrática. Para algunos, la significación de la tradición postmoderna consiste en el peligro que representa para el movimiento de la mujer y para la lucha permanente a favor de su liberación. Si no existe una referencia a las estructuras de la sociedad, si no hay una condición común clara que una a las mujeres a pesar de su diversidad, ¿puede darse acaso algo parecido a una política democrática feminista?

$¿$ Debemos promover, por ejemplo, iniciativas educativas en nombre de la "mujer" como categoría? ¿Es necesario disponer del concepto de "niña" con el fin de luchar para mejorar la educación femenina? ${ }^{50}$

En cierto sentido, estas teorías postmodernas forman parte de una dolencia social más general en la que los valores democráticos parecen tener poco relieve. Como sostiene el Consejo de Ministros del Consejo de Europa, existe en Europa una enfermedad social que es más el resultado de la desintegración y división del orden social que de la ignorancia de los valores democráticos. Ese "desorden" se pone de manifiesto en la alienación de la juventud, la intolerancia, los actos de violencia, el terrorismo, el resurgimiento de la expresión pública de actitudes racistas y xenófobas, la desilusión de muchos jóvenes europeos afectados por la recesión económica y conscientes de la persistencia de la pobreza y la desigualdad en el mundo (Cámara de los Comunes). En el mundo postmoderno, las luchas a favor de la justicia social en la educación y en la sociedad también se han visto afectadas por el rápido crecimiento del capitalismo de las compañías de ámbito mundial, el resurgimiento de la derecha, la fragmentación del bloque oriental y el colapso del socialismo, el surgimiento del nacionalismo y las crecientes desigualdades sociales, tanto entre como dentro de las economías aparentemente avanzadas. ${ }^{51}$

${ }^{50}$ A. Jones, "Becoming a 'Girl': poststructuralist suggestions for educational research", Gender and Education, 5, 2, 1993, p. 157-66.

${ }^{51}$ K. Weiler, "Feminism and the Struggle for a Democratic Education: a view from the United States", en M. Arnot y K. Weiler (eds.), Feminism and Social Justice in Education, 1993, Londres, Falmer Press. 
Sin embargo, a causa de esa anomia cultural y de los cambios políticos y económicos, la política democrática feminista sigue siendo relevante, aunque su fundamento haya cambiado tanto que resulte irreconocible. Como dice Kathleen Weiler, ${ }^{52}$ en el contexto de los Estados Unidos, lo que ahora está en juego es "el futuro de la educación para las mujeres en las sociedades marcadas por el resurgimiento de la ideología derechista y el control conservador del Estado". "Las preocupaciones y las vidas de las mujeres han sido excluidas del discurso neoconservador sobre la educación".

Podemos asistir a esta situación en el Reino Unido, en donde las reformas educativas neoconservadoras han tratado de sustituir los "presuntamente molestos supuestos del Estado democrático liberal" por la visión de una democracia de consumidores. ${ }^{53}$ Esta ruptura fundamental con el discurso democrático liberal de la democracia tiene consecuencias para las escuelas y para quienes luchan por cambiarlas.

Como dice Weiler, estamos participando ahora en una batalla con respecto al significado de la educación y la democracia entre quienes buscan una sociedad más participativa por igual y más justa y quienes restringirían a las élites el acceso al saber y al poder. Como sabemos,

114 los objetivos igualitarios no tienen por qué ser compatibles con los principios económicos. De hecho, en una revisión de la democracia como ideal mundial, "estaba claro que, en el siglo XX, la ciudadanía y el sistema capitalista han estado en guerra". ${ }^{54}$ Los políticos han explotado esa guerra y sobre todo la Nueva Derecha ha resaltado la incompatibilidad entre el concepto de ciudadanía social (a la que nos referimos antes) y la prosperidad en las economías capitalistas.

En los últimos cinco años, la solución propuesta por el gobierno conservador del Reino Unido ha consistido en desarrollar un discurso

52 Ibidem, p. 210.

${ }^{53}$ S. Ransom, "From 1944-1988: Education, Citizenship and Democracy", en M. Flude y M. Hammer (eds.), The Education Reform Act: its origins and implications, 1988, Londres, Falmer Press.

${ }^{54}$ D. Heater, op. cit., p. 101. 
de ciudadanía democrática que privilegia la elección y la rendición pública de cuentas, ${ }^{55}$ los deberes y responsabilidades individuales sobre los derechos. ${ }^{56}$ La democracia se basa ahora en la libertad de elección privada, en la competición y el progreso individual. No aparece la idea de bien común; en realidad, como decía Margaret Thatcher, en cuanto sociedad, no existe tal cosa.

En 1988, los ministros británicos conservadores comenzaron a promover lo que llamaban ciudadanía activa, resaltando la difusión del poder, las obligaciones civiles y el servicio voluntario. ${ }^{57}$ Hay que estimular a los individuos mediante la educación para la ciudadanía, cursos que reafirmen en los deberes del individuo para que sea promotor activo de la salud de la nación. La libertad individual quedaría garantizada al eliminarse las interferencias del Estado, sobre todo en el nivel de la comunidad local.

No obstante, la introducción de la educación para la ciudadanía (aunque basada en su formación con respecto a las responsabilidades individuales) brinda oportunidades a quienes luchan por los derechos de las mujeres. La consecuencia positiva constituirá, si se aprovecha, la ocasión para educar a los niños en la historia política, alertándolos acerca: del papel activo desempeñado por las mujeres al luchar por sus derechos, de los valores y estructuras de la esfera privada y de la posición que en ella ocupa la mujer, y de la procedencia de los obstáculos para la consecución de esos derechos. Asimismo, podriamos incluir en el saber escolar la diversidad de culturas, la historia de las luchas politicas y la rica humanidad de todos los miembros de la sociedad. ${ }^{58}$

Por tanto, la naturaleza y la búsqueda de la democracia, en la medida en que afectan a las mujeres, siguen siendo temas clave en países como Gran Bretaña. Al cuestionar las ideas de la ciudadanía social, la Nueva Derecha ha destruido el fundamento de muchas reformas efec-

\footnotetext{
${ }^{55} \mathrm{~S}$. Ransom, op. cit.

${ }^{56} \mathrm{D}$. Heater, op. cit.

${ }^{57}$ Ibidem.

${ }^{58} \mathrm{~K}$. Weiler, op. cit.
} 


\section{MADELEINE ARNOT}

tuadas en nombre de la igualdad entre los sexos. Se aplaudirá más el logro de una mujer individual que el progreso de las mujeres como grupo. ${ }^{59}$ La responsabilidad de la reforma y el progreso sociales vuelve a recaer con toda claridad en cada mujer. Y en ese contexto, las diferencias de clase y étnicas entre las mujeres se convierten en determinantes críticos de su éxito.

Al mismo tiempo, el feminismo postmoderno ha cuestionado la relevancia de definiciones de la ciudadanía precedentes, que universalizaban e, incluso, omitían la especificidad y multiplicidad de las demandas de las mujeres. Como dice Chantal Mouffle, ${ }^{60}$ las antiguas versiones de "ciudadanía" se han convertido en obstáculo para que la democracia funcione de una manera inclusiva más auténtica. Por tanto, no podemos ir hacia atrás para defender los conceptos universales y de orientación masculina de democracia y de educación democrática.

Las feministas podemos escoger entre dos vías. Por una parte, podríamos elaborar un nuevo concepto de ciudadanía, neutral con respecto al género, generalizable e inclusivo. Por otra, podríamos aceptar y construir una teoría de la diferencia sexual. Como dice Carol Pateman:

Para que las mujeres sean ciudadanas, en cuanto mujeres, autónomas, iguales, aunque sexualmente diferentes de los hombres, la teoría y la práctica democráticas han de sufrir una transformación radical (...) la democracia no puede ser coto de los hombres. ${ }^{61}$

Es obvio que todavía queda mucho por debatir en relación con la medida en que la diferencia de género deba informar nuestro trabajo

${ }^{59}$ Cfr. M. Arnot, "Feminism..., op. cit. y "A crisis..., op. cit.

${ }^{60}$ C. Mouffle, "Feminism, Citizenship and Radical Democratic Politics", en J. Bulter y J. W. Scott (eds.), Feminist Theorise the Political, 1992, Routledge.

${ }^{61}$ C. Pateman, op. cit. 
como pedagogos. Espero haber puesto de manifiesto algunas dimensiones políticas de este debate. Hemos de considerar con todo detenimiento lo que queremos decir al hablar de democracia en la educación en un contexto marcado por el género. Desde mi punto de vista, ya no es posible dar por supuestas las definiciones de democracia basadas en los principios liberales ni basar la política democrática en los intereses de las mujeres como tales, en su sentido más simple. Cada vez somos más conscientes de que la lucha va en contra de las "múltiples formas en las que la categoría mujer se plantea como subordinada". ${ }^{62}$ Es momento para cambiar nuestras formas de luchar a favor de la justicia social, de abandonar la "piel de león" y crear nuevas definiciones de ciudadanía que estén adaptadas a las mujeres.

${ }^{62}$ C. Mouffle, op. cit. 